\title{
Design and Testing of a Shell-Encapsulated Solar Collector with the Compound Surface Concentrators
}

\author{
Hongfei Zheng, Gang Wu, Jing Dai, and Yanyan Ma \\ School of Mechanical Engineering, Beijing Institute of Technology, Beijing 100081, China \\ Correspondence should be addressed to Hongfei Zheng; 343038311@qq.com
}

Received 23 November 2014; Accepted 31 January 2015

Academic Editor: Yuehong Su

Copyright (C) 2015 Hongfei Zheng et al. This is an open access article distributed under the Creative Commons Attribution License, which permits unrestricted use, distribution, and reproduction in any medium, provided the original work is properly cited.

\begin{abstract}
This paper presents design and testing of a shell-encapsulated solar collector which can be used in north area of China for wallamounting installation. The designed solar collector is based on the combination of a novel compound curved surface concentrator and an aluminum concentric solar receiver, which is contained in a glass evacuated-tube. As there is no perforative joint between the double-skin glass evacuated-tube and the aluminum concentric solar receiver, the difficulty of vacuum keeping for a glass-metal joint is avoided. The cavity shell provides an additional thermal insulation to reduce heat loss of the designed solar collector. The working principle of the compound curved surface concentrator is described. The ray-tracing results are given to show the effect of deviation angle of the concentrator on its optical efficiency, hence determining its maximum acceptance angle. A prototype of the designed solar collector has been constructed and tested under the sunny winter weather condition. The experimental results indicate that the hot water temperature higher than $80^{\circ} \mathrm{C}$ with a daily average efficiency of about $45 \sim 50 \%$ has been achieved at the average ambient temperature below $0^{\circ} \mathrm{C}$, so the designed solar collector can produce hot water at a useful temperature in winter.
\end{abstract}

\section{Introduction}

Generically, there are two types of solar collectors being used widely, that is, conventional flat plate collectors and recently-developed glass evacuated tube collectors. They have their individual advantage and disadvantage. The flat plate solar collectors have the advantages of bearing mechanical stress, no immediate leaking once partly damaged, and easier architectural integration, while their disadvantages are low operating temperature in winter and being subject to the problem of freezing damage. Reversely, the glass evacuated tube collectors can maintain a sufficiently high operating temperature at the ambient temperature below the freezing point in winter; for example, at the outdoor temperature higher than $-10^{\circ} \mathrm{C}$, the collection temperature can exceed $45^{\circ} \mathrm{C}$. However, they have the disadvantage of easily being damaged under mechanical stress especially for the large scale system. The evacuated tube solar collectors have significantly higher efficiency than the flat plate collectors at higher collection temperature or lower ambient temperature owing to vacuum thermal insulation. Zambolin and Del Col [1] had experimentally compared these two types of solar collectors and found that the evacuated tube collector could maintain an efficiency of above $50 \%$ at the average hot water temperature of about $60^{\circ} \mathrm{C}$, ambient temperature of $20^{\circ} \mathrm{C}$, and solar irradiance of $700 \mathrm{~W} / \mathrm{m}^{2}$. Solar concentrators could be used to enhance the thermal performance of the evacuated tube collectors for higher operating temperature application or the situation of low solar irradiation. The concentrationtype solar collector designed by Snail et al. [2] has an optical efficiency of $65 \%$ and a thermal efficiency of better than $50 \%$ at fluid temperatures of $200^{\circ} \mathrm{C}$ without tracking the sun. In comparison, Rabl et al. [3] had studied combination of nonevacuated solar collectors with compound parabolic concentrators (CPC). Li and Wang [4] have investigated a combined trough parabolic concentrator and evacuated tube solar collector system and measured an efficiency of about $70 \%$ at the outlet water temperature of $105^{\circ} \mathrm{C}$. Although the production of CPC optical surfaces can be done only by expensive single-point machining techniques, it is possible to approximate the complex surfaces of the CPC by means of a limited number of simpler shapes without severe efficiency 
losses [5]. Adsten et al. [6] have proposed a so-called MaReCo design of solar concentrators for stationary installation. Norton et al. [7] gave many researches to symmetric and asymmetric linear compound parabolic concentrators which is very useful for us to design some novel concentrators.

On the other hand, in some situation the collector needs be mounted on the wall. For example, in very high building the users hope to fix their solar collector on the south wall if it is available. Ji et al. [8] described a wall-mounted hybrid photovoltaic/water-heating collector. The evacuated tube solar collectors are particularly suitable for wall-mounting installation in the area of high latitude [9]. However, the vacuum tube collector is cram with water which adds its heat mass so that it gives very low temperature hot water in winter. In order to get higher temperature thermal energy, Adsten et al. (2005) evaluated various asymmetric CPC designs for stand-alone, roof or wall-mounted installations. Mills et al. [10] also researched the characteristics of asymmetric CPC solar collectors with tubular receiver and indicated that they can be used in some special occasion.

In addition, the receiver used in the compound parabolic concentrator is very important. Mills et al. [10] discussed the problems about evacuated tube solar receivers mounted in special concentrator. Tripanagnostopoulos et al. [11] also discussed the problem about CPC solar collectors coupling with flat bifacial absorbers. All of the previous work is to pursuit the higher working temperature of the collector or let the collectors be able to operate in winter.

This study will present design and testing of a new-type solar collector based on incorporation of a novel compound curved surface concentrator with an aluminum concentric solar receiver enclosed in a glass evacuated tube. The designed solar collector would be suitable for wall-mounting installation in the area of high latitude.

\section{Design of the System}

The use of a novel compound curved surface solar concentrator is a key element in the design of a new-type solar collector hot water system for wall-mounting installation. Combined with the glass evacuated tube solar receiver, the solar collector system would be able to provide hot water at the temperature of above $70^{\circ} \mathrm{C}$ in the winter. The detailed innovative design is described as follows.

2.1. Design of the Compound Curved Surface Concentrator. The key component of the proposed new-type solar collector system is a novel trough-type compound curved surface concentrator; the cross-section of which is shown in Figure 1. The compound concentrator consists of two upper parabolic mirrors formed from a paraboloid "1," two plane mirrors "2," and a parabolic mirror " 3 " at the base. The heights of the two upper parabolic mirrors are not equal to give a tilted aperture, the angle of which is associated with geographic latitude. The central line of a tubular receiver " 4 " overlaps with the focus line of the paraboloid "1" while it may slightly be above the focus line of the paraboloid " 3 ." The incoming rays within a certain angle to the symmetrical axis of the concentrator are mainly reflected by the upper parabolic

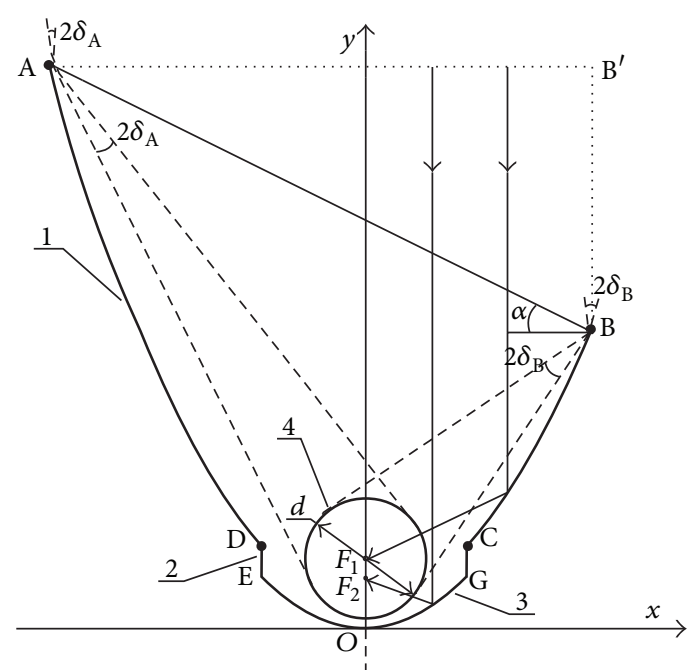

FIGURE 1: A cross-sectional view of the compound curved surface concentrator.

mirrors to the receiver " 4 " and the rest are reflected by the plane mirrors and the base parabolic mirror, which may rereflect the reflected rays from the mirrors "1" to the receiver " $4 . "$

2.1.1. Design Considerations. On the cross-section of the concentrator as shown in Figure 1, $A D$ and $B C$ are the left and right sections of the parabolic curve " 1 " with its focus on the point $F_{1}$, which is described by

$$
2 p_{1}(y-l)=x^{2}, \quad\left(\text { for upward opening, } p_{1}>0\right),
$$

where $p_{1}$ is the focal parameter and $l$ is the vertical distance from the vertex of the parabolic curve " 1 " to the $x$-axis.

The parabolic curve is truncated with straight line $A B$, which, therefore, forms the aperture of the parabolic curve. The tilt angle $\alpha$ of the line $A B$ may be the same as local geographic latitude. The straight line segments $D E$ and $C G$ are vertical to the $x$-axis and symmetrical about the $y$ axis. The distance between $D E$ and $C G$ and their reasonable lengths are chosen in accordance with the diameter of the tubular receiver and also in order to maximize the acceptance angle. $E O G$ is a section of the parabolic curve " 3 " with its focus at the point $F_{2}$ and its vertex on the $x$-axis. The EOG is described by

$$
2 p_{2} y=x^{2}, \quad\left(\text { for upward opening, } p_{2}>0\right),
$$

where $p_{2}$ is the focal parameter. Therefore, the cross-section of the compound curved surface comprises of the parabolic curved segments $A D$ and $B C$, straight line segments $D E$ and $C G$, and parabolic curved segment $E O G$.

2.1.2. Geometric Concentration Ratio and Maximum Acceptance Angle. As shown in Figure 1, the two angles $2 \cdot \delta_{A}$ and $2 \cdot \delta_{B}$ are formed between the tangent lines from the points 
$A\left(x_{A}, y_{A}\right)$ and $B\left(x_{B}, y_{B}\right)$ to the cross-section circle of the receiver " 4 ." They are given by

$$
\begin{aligned}
& \sin \delta_{A} \approx \frac{d / 2}{\sqrt{\left(x_{F_{1}}-x_{A}\right)^{2}+\left(y_{F_{1}}-y_{A}\right)^{2}}}=\frac{d / 2}{\sqrt{\left(x_{A} / 2 p_{1}\right)^{2}+p_{1}^{2}}}, \\
& \sin \delta_{B}=\frac{d / 2}{\sqrt{\left(x_{B}-x_{F_{1}}\right)^{2}+\left(y_{B}-y_{F_{1}}\right)^{2}}}=\frac{d / 2}{\sqrt{\left(x_{B} / 2 p_{1}\right)^{2}+p_{1}^{2}}} .
\end{aligned}
$$

As $x_{A}^{2}>x_{B}^{2}$, there is $\delta_{A}<\delta_{B}$. It is obvious that angle $\delta_{A}$ or angle $\delta_{B}$ represents the maximum allowable deviation angle of the concentrator's symmetrical axis from the incoming rays in order to reflect the rays from point $A$ or point $B$ to the tubular receiver " 4 ." Relative to the normal incidence rays the inclined incoming rays from the left may hardly strike on the mirror $A D$, so $\delta_{A}$ may be considered as the lower acceptance angle of the concentrator. All the inclined incoming rays from the right at the deviation angle which is no larger than $\delta_{A}$ can be directly reflected to the receiver by the parabolic mirror $A D$. Similarly, $\delta_{B}$ may be considered as the upper acceptance angle of the concentrator. In fact, each point on the parabolic mirrors $A D$ and $B C$ has its individual maximum allowable deviation angle. According to (3), the individual maximum allowable deviation angle obviously increases when the point is moving down. Therefore, when the deviation angle is larger than $\delta_{A}$ or $\delta_{B}$, part of the incoming rays can still be reflected directly to the receiver by the lower part of the parabolic mirrors $A D$ and $B C$ and some other may reach the receiver through the second reflection by the plane mirror " 2 " and base parabolic mirror " 3 ." For this reason, the maximum acceptance angle $\delta_{\max }$ could be much larger than $\delta_{A}$ and $\delta_{B}$. A little more detail about $\delta_{\max }$ will be discussed in the following section. If the tilt angle of the compound curved surface concentrator is adjusted to follow the sun, the angle $\delta_{A}\left(<\delta_{B}\right)$ could be used to determine the time interval for adjusting the tilt angle. In other words, this angle can also represent the maximum allowable tracking deviation.

The geometrical concentration ratio of the compound curved surface concentrator may be defined as

$$
C=\frac{\overline{A B}}{\pi d},
$$

where $\overline{A B}$ is the width of the aperture $A B$ and $d$ is the diameter of the tubular receiver. If using the width of the aperture $A B$ and the diameter of the tubular receiver to define the geometrical concentration ratio, then $C$ is $C=\overline{A B} / d$.

Equations (1)-(4) may be used to determine the acceptance angle and geometrical concentration ratio of the concentrator for a given geometry. For example, assuming that the concentrator had the following geometrical parameters, $d=50 \mathrm{~mm}, l=12 \mathrm{~mm}, p_{1}=44, p_{2}=50, x_{B}=108 \mathrm{~mm}$, and $\alpha=26.5^{\circ}$, there is that $\delta_{A}=6^{\circ}$. The maximum receiving angle $\delta_{\max }$ is $18^{\circ}$, and the geometric concentrating ratio $C=1.84$ (for the perimeter of the tubular receiver) or $C=5.8$ (for the diameter of the tubular receiver).

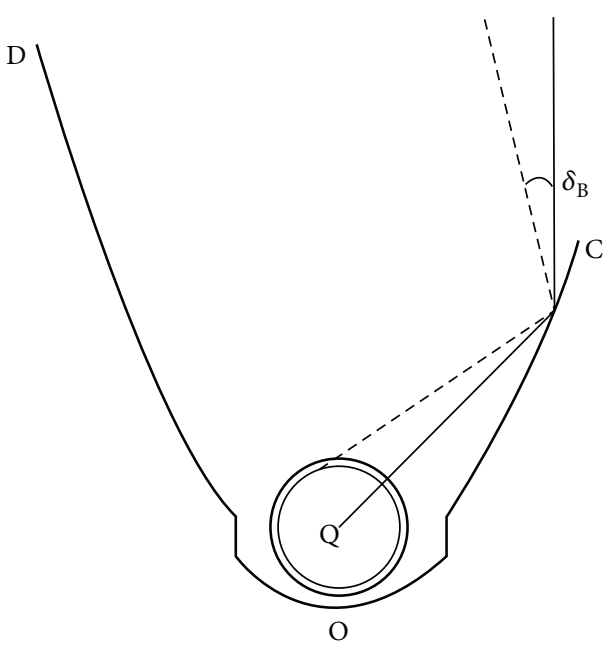

FIGURE 2: Illustrated diagram of tracking error.

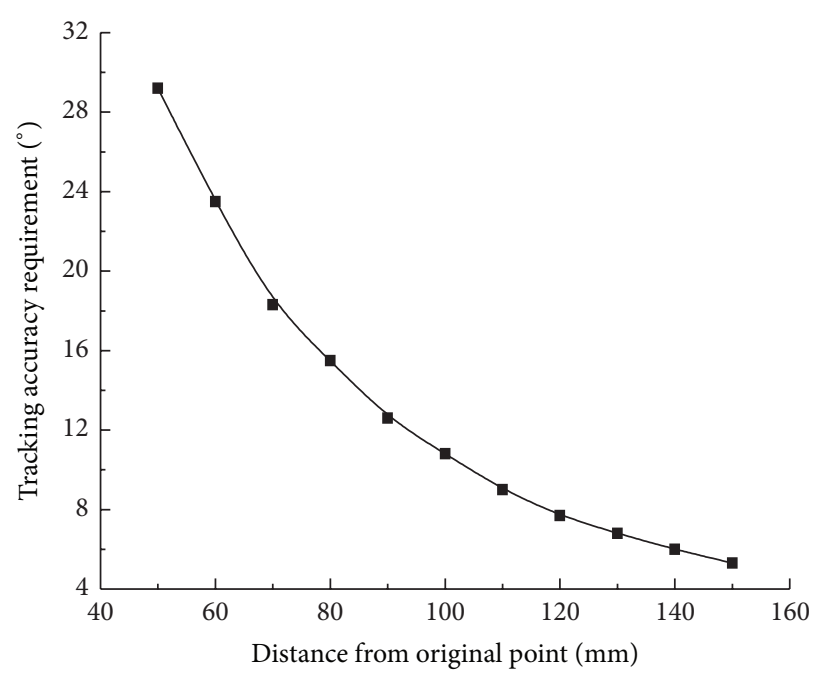

FIGURE 3: Variation of tracking accuracy requirement with the distance.

2.1.3. Tracking Accuracy Requirement. Ideally, if the trough concentrator could track the sun accurately, all incoming sunlight would be reflected by the trough surface to the focus, reaching the receiver. However, there is a tracking error, that is, the symmetrical axis of the trough being deviated from the sunlight as shown in Figure 2. For any receiver being used, there is a maximum allowable deviation angle which may depend on the position on the trough surface. This angle actually represents tracking accuracy requirement for a certain point. As seen from Figure 2, the maximum deviation angle $\delta$ changes with the position of point on the trough surface.

For the design parameters described in the previous section, the variation of $\delta$ with the position of point was computed and shown in Figure 3. It is clear that the tracking accuracy requirement for different point is different. For example, the tracking accuracy was $9.3^{\circ}$ when the distance from original point is $108 \mathrm{~mm}, 5.3^{\circ}$ for $143.7 \mathrm{~mm}$ distance. 


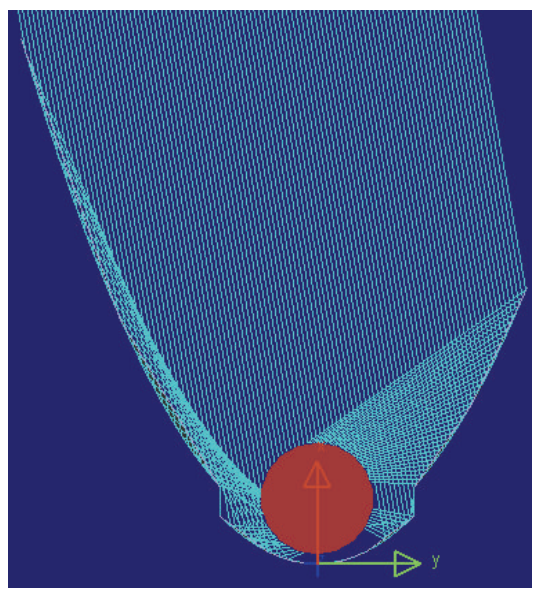

Clockwise deviation by $10^{\circ}$

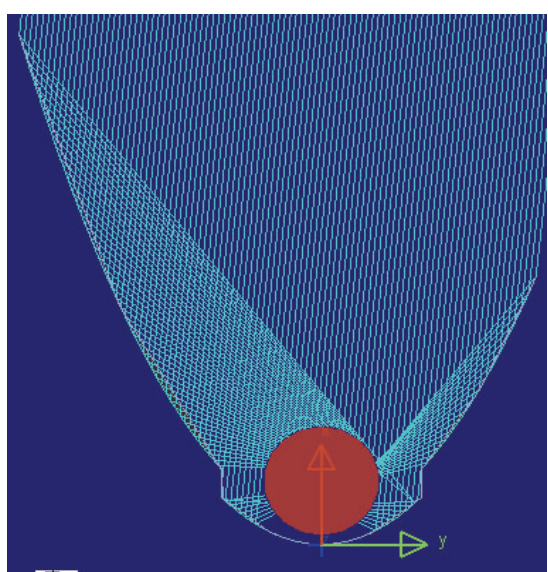

Anticlockwise deviation by 6

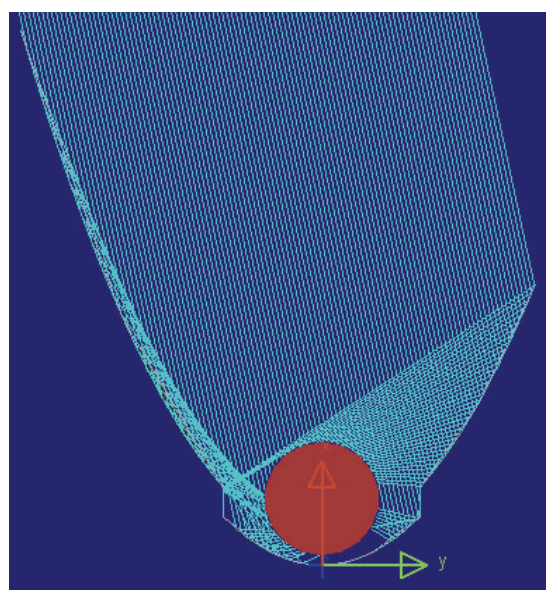

Clockwise deviation by $12^{\circ}$

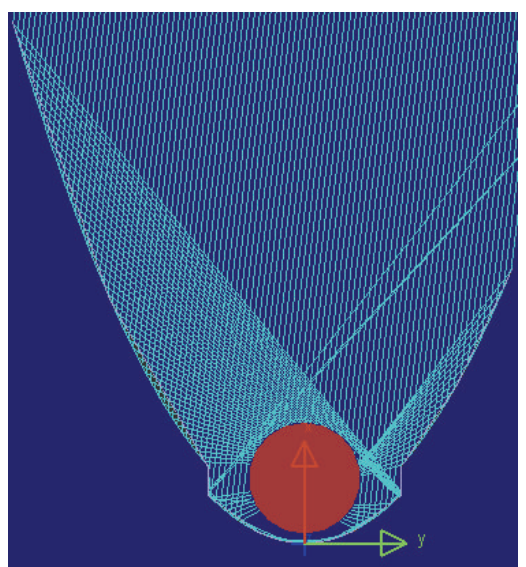

Anticlockwise deviation by 7

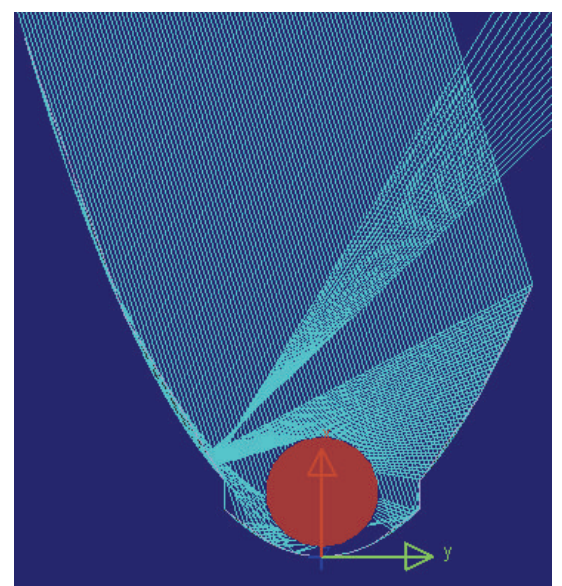

Clockwise deviation by $17^{\circ}$

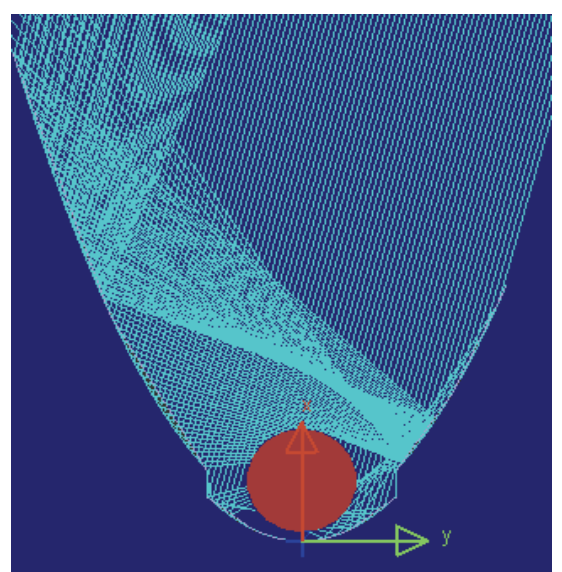

Anticlockwise deviation by $15^{\circ}$

FIGURE 4: Ray-tracking for various deviation angles of the concentrator.

It can be found that the tracking accuracy requirement will be higher when a reflection point is more distant from the focus point. The minimum value of these calculated maximum allowable deviation angle may be considered as the tracking accuracy requirement of the whole trough if all incoming sunlight is expected to reach the receiver.

2.1.4. Ray-Tracing Analysis. The compound curved surface concentrator with the above assumed geometrical parameters was modeled in the $3 \mathrm{D}$ design software Pro/ENGINEER, and the physical model was saved as IGES format and then was imported into the optical simulation software LightTools for ray-tracing analysis. The incident rays were assumed to be parallel and the number of rays was set at 100. Ray-tracing simulation was performed for various deviation angles. Figure 4 shows the ray-tracing results for the clockwise deviation angles of $10^{\circ}, 12^{\circ}$, and $17^{\circ}$ and the anticlockwise deviation angles of $6^{\circ}, 7^{\circ}$, and $15^{\circ}$.

It is apparent that the deviation angle affected the number of the rays reaching the receiver. In order to compare this effect between different deviation angles, it would be convenient to define an ideal optical efficiency which is the ratio of the number of rays reaching the receiver to the total number of incoming rays. According to the results of ray-tracing analysis, the relationship between the ideal optical efficiency and deviation angle can be obtained and is shown in Figure 5. It can be seen that when the deviation angle of the concentrator's symmetrical axis is between $12^{\circ}$ clockwise and $6^{\circ}$ anticlockwise, all incoming rays can reach the receiver; the ideal optical efficiency is 1.0 . When it is $17^{\circ}$ clockwise, the ideal optical efficiency is 0.81 , and when it is $17^{\circ}$ anticlockwise the ideal optical efficiency is only 0.58. The reason for this difference could be explained as follows: as discussed in the previous section, the individual maximum allowable deviation angle of each point on the parabolic mirrors " 1 " decreases when the point is moving up. As the height of the leftward parabolic mirror is larger than the rightward parabolic mirror, the average maximum allowable deviation angle of the leftward parabolic mirror is smaller than the rightward one; hence less percentage of the incoming rays are reflected to the receiver when the deviation angle is larger than $\delta_{A}$ and $\delta_{B}$. It can be also expected that the complete curve of the ideal optical efficiency would look almost symmetrical crossing the vertical line $\overline{a b}$ which passes through the clockwise deviation angle about $2.5^{\circ}$, shown as in Figure 5. But actually the rightward section of curve is slightly 


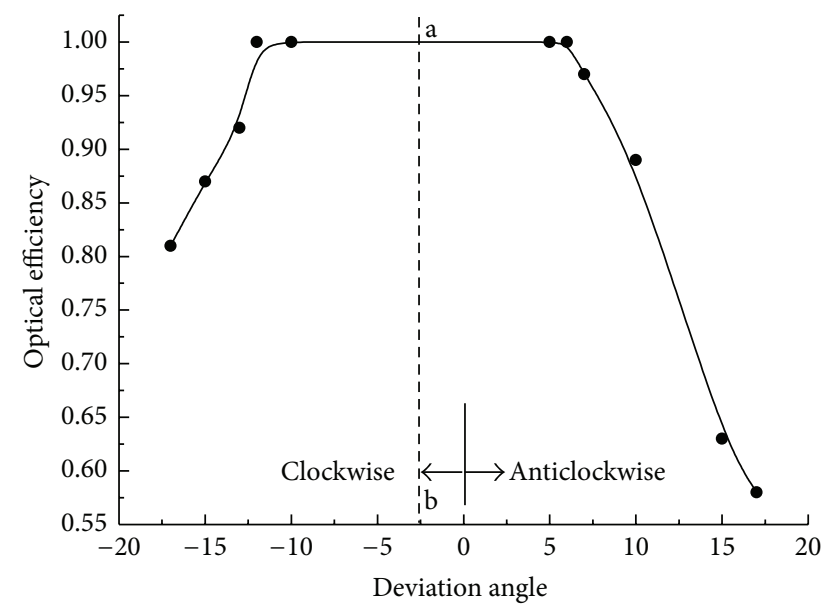

Figure 5: The relationship between the ideal optical efficiency and deviation angle of the concentrator.

steeper than the leftward section. The two end points of the flat section of the curve are corresponding to the upper and lower acceptance angle. The maximum acceptance angle may be determined by extending the efficiency curve to intercept with the $0 \%$ efficiency line. It is worthwhile to mention that Figure 5 would look somewhat different if a fixed density of rays instead of a given number is chosen for ray-tracing analysis.

2.2. Design of the Sun Tracking System. Seen from Figure 5, the designed compound surface concentrator has a clockwise acceptance angle of $13.5^{\circ}$ and anticlockwise acceptance angle of $9.5^{\circ}$, in which the optical efficiency is more than $90 \%$. It will give an overall acceptance angle of $23^{\circ}$. So, sun tracking is necessary in order that the concentrator could collect the direct solar radiation as much as possible. For the wallmounting installation, if the biggest solar altitude angle is $90^{\circ}$, then the daily adjustment number for tracking the sun is only $90 / 23 \approx 4$ times. In winter, it mostly need not adjust the angle because the solar altitude angle is small. For the designed solar collector, it was intended to use a single-axis automatic solar tracking system with the tracking accuracy of about $2^{\circ}$ and the tracking time interval of thirty minutes in accordance with the anticlockwise acceptance angle of $9.5^{\circ}$. This tracing system adopts the light-operated excitation mode.

2.3. Design of the Receiver. The solar receiver is another key component. A double-skin glass evacuated tube incorporated with a concentric aluminum pipe was used as the solar receiver. The outer dimension of the glass evacuated tube was $58 \mathrm{~mm} \times 2100 \mathrm{~mm}$. The concentric aluminum pipe includes two layers as shown in Figure 6. The outer aluminum has a diameter of $42 \mathrm{~mm}$ and a length of $1900 \mathrm{~mm}$, and its outer surface was coated by an oxidation film to form an effective tubular solar absorption surface. Compared with the conventional finned U-tube solar absorbers, the concentric absorber has an annular water channel on the inside of the tubular solar absorption surface, so the thermal resistance could be minimized. In addition, the double-skin glass evacuated tube does not have any perforative junction with the aluminum concentric pipe; hence the possibility of vacuum leakage could also be minimized.

2.4. Design of the Shell-Encapsulated Solar Collector. The schematic structure and experimental prototype of the designed solar collector are shown in Figure 7. The solar collector is comprised of an encapsulation shell "1," a combined manual and automatic tracking mechanism " 2 and 3," several small-size trough-type compound curved surface concentrators "4," a glass cover "5," and several glass evacuated tube solar receivers " 6. " The working principle of the solar collector is as follows: (1) the solar rays are incident on the compound curved surface collector " 4 " through the glass cover " 5 "; (2) the rays are reflected to the surface of the receiver " 6 "; (3) the solar radiation is transformed into heat through absorption by the selective coating on the outer aluminum pipe; (4) the heat transfer fluid enters the inner tube of the concentric aluminum pipe, and then it flows into the annular channel between the middle pipe and outer pipe, where it absorbs heat and its temperature increases along the channel; (5) the heat transfer fluid transports heat to the hot water storage tank through the circulation line, and it releases heat to water through the immerged coil heat exchanger to increase the water temperature. Compared with the common evacuated tube solar collectors, the designed concentration-type solar collector uses less number of evacuated tubes for the same solar collection area, so the overall amount of heat transfer fluid in the tubes could be reduced. This may help reduce the overall thermal inertia and hence lead to a fast thermal response. Due to the use of solar concentration, the solar collector may be able to provide a usable water temperature in the cold winter and is not subject to the frosting problem, so it is especially suitable for the high-latitude regions and winter with a smaller solar elevation angle.

The dimension of the prototype wall-mounting solar collector was $2.3 \mathrm{~m} \times 2.0 \mathrm{~m} \times 0.3 \mathrm{~m}$. The inside of the encapsulation shell was attached with a cystosepiment board of about $20 \mathrm{~mm}$ thick and a thin layer of glass wool as the thermal insulation layer to reduce heat loss. The solar collector included four trough-type compound curved surface concentrators. The tracking system was behind the trough concentrators, so it was seen from outside. Each trough concentrator had a width of $260 \mathrm{~mm}$ and a length of $1900 \mathrm{~mm}$ to give an aperture area of $0.494 \mathrm{~m}^{2}$. The reflecting surface of the concentrators had about $92 \%$ reflectance with the diffuse reflectance less than $10 \%$ and specular reflectance equaling $88 \%$. The glass cover and encapsulation shell was jointed to form an enclosed cavity. The glass cover was a $4 \mathrm{~mm}$ thick low-iron float flat glass with the light transmittance of 0.88 that exceeds the requirement of GB 11614-2009 (China's Nation Standard and Profession Standard for flat glass). Although the glass cover reduces the amount of solar radiation entering the solar collector, it provides dust-proof for the concentrators and the enclosed cavity could help reduce heat loss from the evacuated tube solar receiver. 


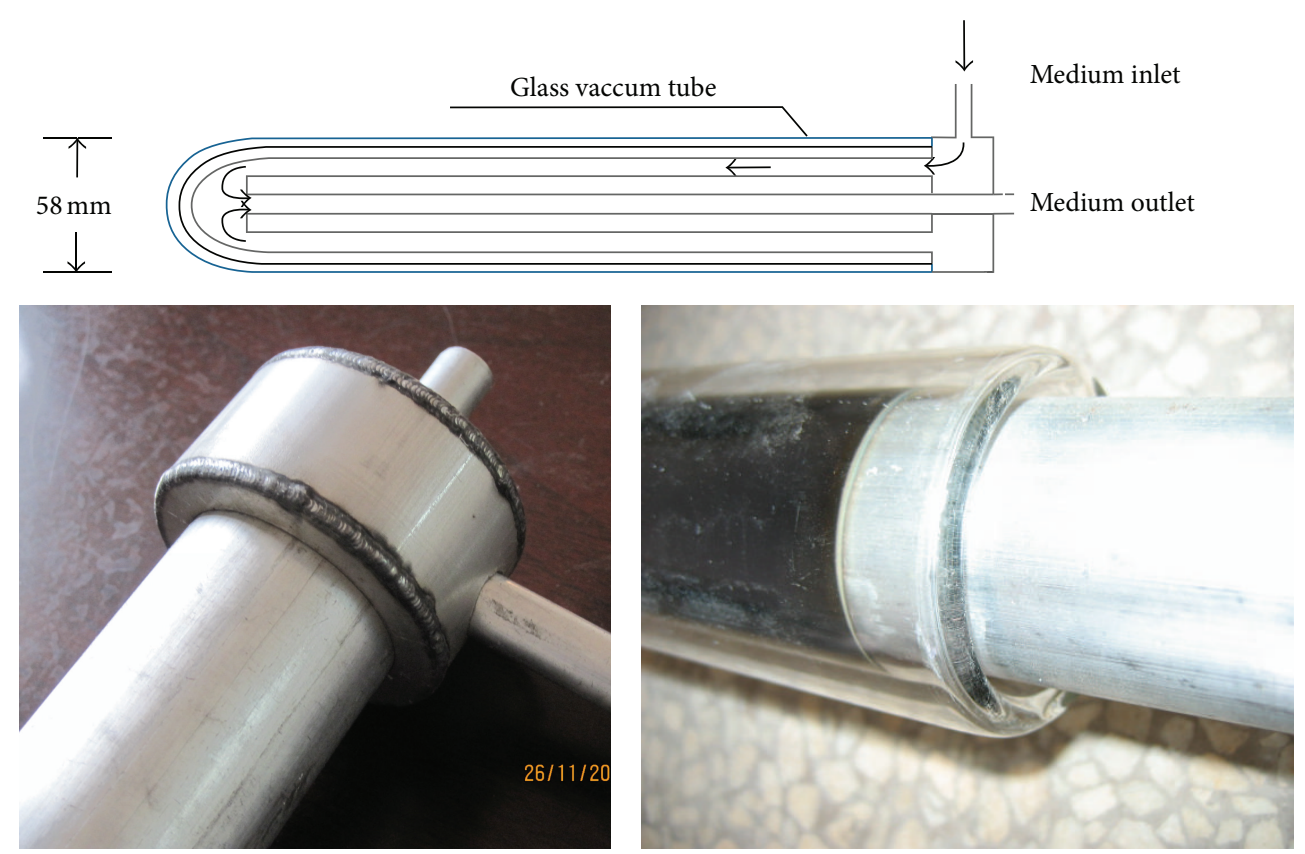

FIgURE 6: An aluminum concentric pipe receiver comprising of a glass evacuated tube.

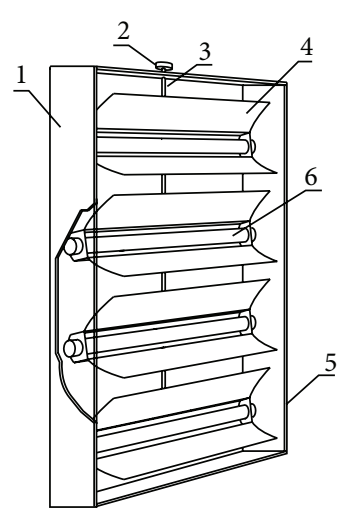

(1) Packaging shell;

(2) Manual regulation tracker;

(3) Draw bar;

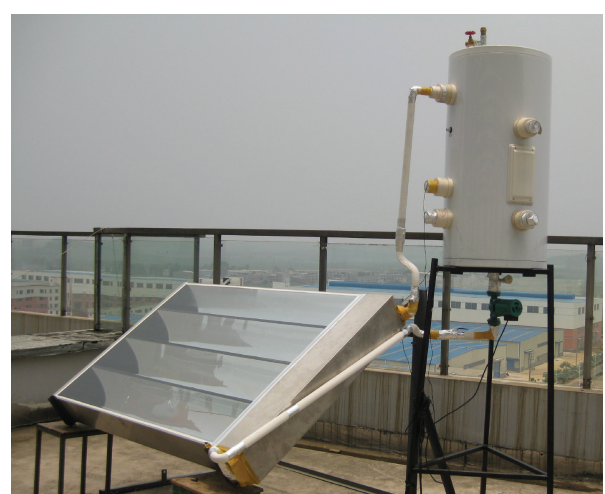

(4) Compound curved surface concentrators;

(5) Glass cover;

(6) Glass evacuated-tube collector

FIGURE 7: The schematic structure and photo of the prototype shell-encapsulated solar collector.

\section{Performance Testing of the Prototype Solar Collector}

3.1. Experimental System. As shown in Figures 7 and 8, the experimental system included a prototype wall-mounting shell-encapsulated solar collector, a water tank, a circulation pump, a feed container, a heat exchange coil, and a circulation pipe. A $20 \mathrm{~mm}$ thick thermal insulation layer was applied to the circulation line and water tank to reduce heat loss. The working principle of the experimental system is as follows: the incoming solar radiation is concentrated and collected by the solar collector to heat up the heat transfer fluid inside; then the heated working fluid flows to the water tank where its heat is released to the water. The cooled working fluid after heat release is circulated by the pump to the solar collector to be heated again. With the process continuing, the water temperature in the water tank gradually rises. When it reaches to a certain degree, it is ready to be used.

The performance testing was conducted in Beijing $\left(\mathrm{N} 39^{\circ} 57^{\prime}, \mathrm{E} 116^{\circ} 19^{\prime}\right)$ with the ambient temperature in the range of $-1 \sim-9^{\circ} \mathrm{C}$. The volume of the water tank was $80 \mathrm{~L}$ with an initial water temperature at $11.6^{\circ} \mathrm{C}$. In the experiment, the solar irradiance was automatically recorded by a TRM-2 solar test system (including the TBQ-DI solar radiation table) with the accuracy $\pm 5 \%$. The calibrated k-type thermocouples were used to measure temperatures at various points on 


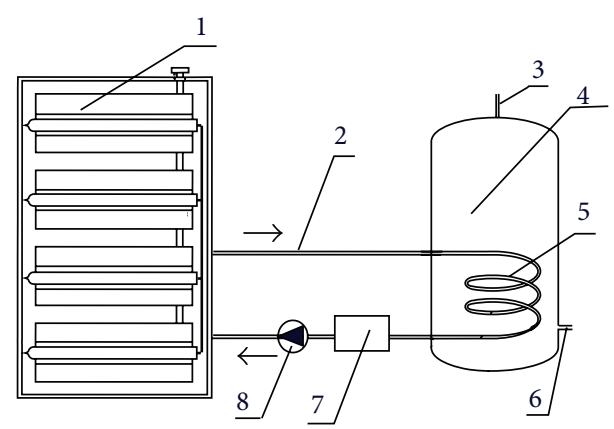

(1) A novel compound curved surface concentrator;

(2) Circulating pipe;

(3) Water outlet;

(4) Water tank;

(5) Heat exchange coil;

(6) Water inlet;

(7) Oil tank;

(8) Pump

FIGURE 8: Schematic experimental system for testing the prototype shell-encapsulated solar collector.

the system. The data were recorded by a TT-12 temperature data logger, in which reading interval could be adjusted.

\subsection{Experimental Results and Analysis}

3.2.1. Efficiency Testing. In order to validate the designed solar collector for application in winter, two days with lower ambient temperature were chosen for the experiment. The prototype solar collector was placed vertically to simulate the wall-mounting installation. The system was in automatic tracing model. The ambient and water temperatures and solar irradiance on vertical plane were recorded every $20 \mathrm{~min}$. The recorded data are shown in Figures 9 and 10.

It can be seen from the solar irradiance values in Figure 9 that two chosen days for testing were sunny and cloudless, but the ambient temperature was below $-1^{\circ} \mathrm{C}$. As shown in Figure 10, the prototype solar collector had heated the storage water up to nearly $80^{\circ} \mathrm{C}$ by 3:00 pm, so it could fully meet the requirement of domestic hot water in winter in colder areas. The water temperature almost increased linearly with time at the beginning and exceeded $65^{\circ} \mathrm{C}$ at around $2: 00 \mathrm{pm}$, and then the rate of temperature rise began to decrease because the solar radiation started to decrease in the afternoon while the heat loss of the system continued to increase with the increasing water temperature. It can also be seen that the enclosed cavity generally had a temperature of above $20^{\circ} \mathrm{C}$. This would clearly help to reduce heat loss to the ambient compared with the situation of exposing the evacuated tube solar receivers to the ambient temperature of below $0^{\circ} \mathrm{C}$ in the winter.

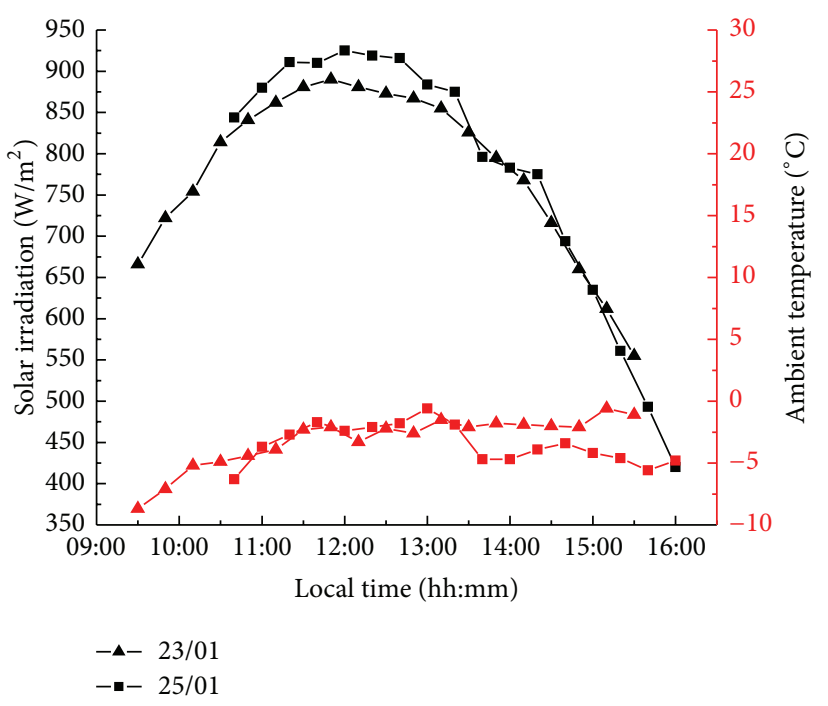

FIGURE 9: Change of the solar irradiance and ambient temperature with local time.

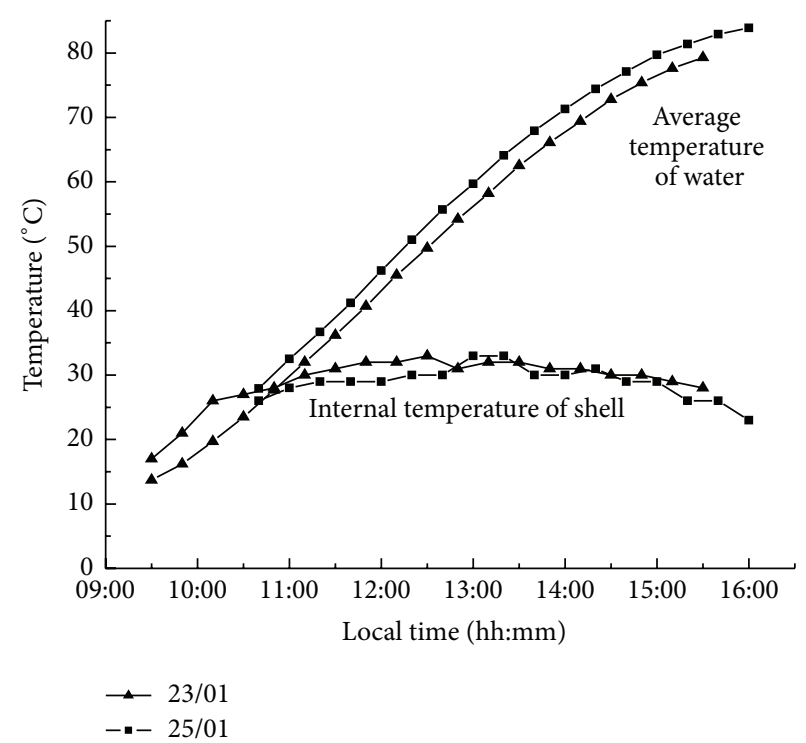

FIGURE 10: Change of water temperature and shell inside temperature with local.

The daily average efficiency is a key parameter to characterize a solar collector, and it may be defined as follows:

$$
\eta_{d}=\frac{M C_{p}\left(t_{e}-t_{s}\right)}{A_{c} H},
$$

where $\eta_{d}$ is the daily average efficiency, $M$ and $C_{p}$ are the amount and specific heat of water, $t_{s}$ is the initial average temperature of the water tank $\left({ }^{\circ} \mathrm{C}\right), t_{e}$ is the final temperature of the water tank $\left({ }^{\circ} \mathrm{C}\right), \mathrm{H}$ is the daily cumulative solar radiation exposure $\left(\mathrm{MJ} / \mathrm{m}^{2}\right)$, and $A_{c}$ is the aperture area of the solar collector, which was $2.47 \mathrm{~m}^{2}$.

Substituting the experimental data into (5) gives the daily average efficiency of $51.3 \%$ for the 23rd of January and $50.1 \%$ 


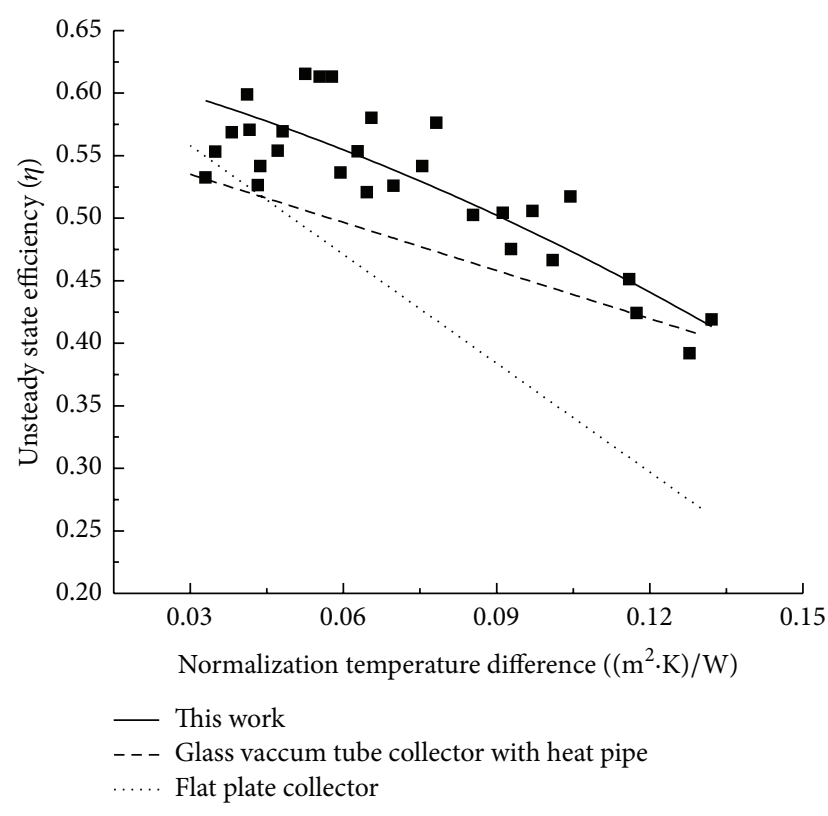

FIGURE 11: Unsteady-state efficiency curves for three types of solar collectors.

for the 25th of January, respectively. The small difference in the efficiencies for these two days may be due to the difference in the average operating temperatures.

The transient efficiency is a reflection of thermal conversion efficiency changing with time, and it may be defined as $[12]$

$$
\eta=\frac{M C_{p}\left(t_{i+1}-t_{i}\right)}{A_{c}\left(H_{i+1}-H_{i}\right)}
$$

where $\eta$ is the transient efficiency, $M$ is the water mass in the water tank $(\mathrm{kg}), A_{c}$ is the aperture area of the solar collector $\left(\mathrm{m}^{2}\right), C_{p}$ is the specific heat of water $\left(\mathrm{kJ} \cdot \mathrm{kg}^{-1} \cdot{ }^{\circ} \mathrm{C}^{-1}\right), t$ is the average water temperature in the water $\operatorname{tank}\left({ }^{\circ} \mathrm{C}\right), \mathrm{H}$ is the cumulative solar irradiation $\left(\mathrm{MJ} / \mathrm{m}^{2}\right)$, and the subscripts $i+1$ and $i$ stand for the start state and end state of each time interval.

By inserting the experimental data into (6), the transient efficiency $\eta$ at different time can be obtained and plotted against the normalized temperature difference $\left(t_{m}-t_{a}\right) / I$ as shown in Figure 11. The transient efficiency displays an approximate quadratic relationship with the normalized temperature difference. The least square regression of the data in Figure 11 gave the following formula:

$$
\eta=0.632-0.983 T_{i}^{*}-5.084 T_{i}^{* 2} .
$$

Figure 11 also shows the transient efficiency curves for an efficient flat solar collector [13] and an evacuated tube heatpipe solar collector for comparison [14]. It can be seen that when the water temperature equals the ambient temperature, that is, $\left(t_{m}-t_{a}\right) / I=0$, the $y$ intercept of the transient efficiency curve of the designed solar collector is 0.632 , which is higher than the other two solar collectors. This indicates

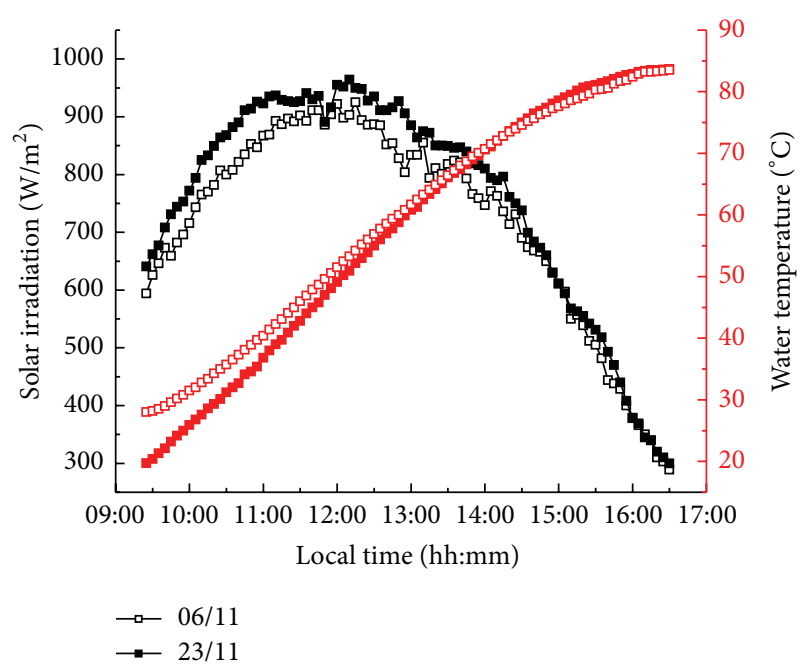

FIGURE 12: The change trend of solar irradiance and water temperature with local time.

that the heat loss of the designed solar collector might be considerably reduced due to the use of the solar concentrator and cavity shell. The transient efficiency curves of three solar thermal collectors are in a common trend; that is, with the rise of the operating temperature their efficiencies decrease at different slopes, among which the efficiency curve of flat solar collector has the steepest slope. The slope of the efficiency curve of the designed solar collector is similar to that of the common evacuated tube heat-pipe solar collector but is slightly lower at higher temperature. This is mainly because the thermal insulation of the designed solar collector is not as good as that of the common evacuated tube solar collector; thus a considerable amount of heat is lost at the water tank and circulation pipe.

The system was also tested in the nontracking mode for comparison, in which the trough was fixed during a day test. But the tilt angle (between the symmetrical axis of the trough and the ground) was adjusted between different days. For example, the angle was $50^{\circ}$ on 6 th of November and $40^{\circ}$ on 23rd of November, respectively. Other conditions were the same as that of automatic tracing mode.

The experimental results on two typical shiny days are given in Figure 12. Based on the data, the daily efficiency is calculated to be $44.5 \%$ and $38 \%$, respectively. This indicates that the tilt angle has important influence on the efficiency. Compared with the efficiency of about 50\% for the tracking mode, it can be seen that use of sun-tracking is important for obtaining a high efficiency.

The measuring error of experiment was analyzed. The differential operation is used in solving (5). Variation of efficiency gave the following formula:

$\Delta \eta$

$$
=\frac{C_{p}}{A_{c}}\left[\frac{M}{H} \Delta t_{e}+\frac{M}{H} \Delta t_{s}+\frac{\left(t_{e}-t_{s}\right)}{H} \Delta M+\frac{M\left(t_{e}-t_{s}\right)}{H^{2}} \Delta H\right] .
$$




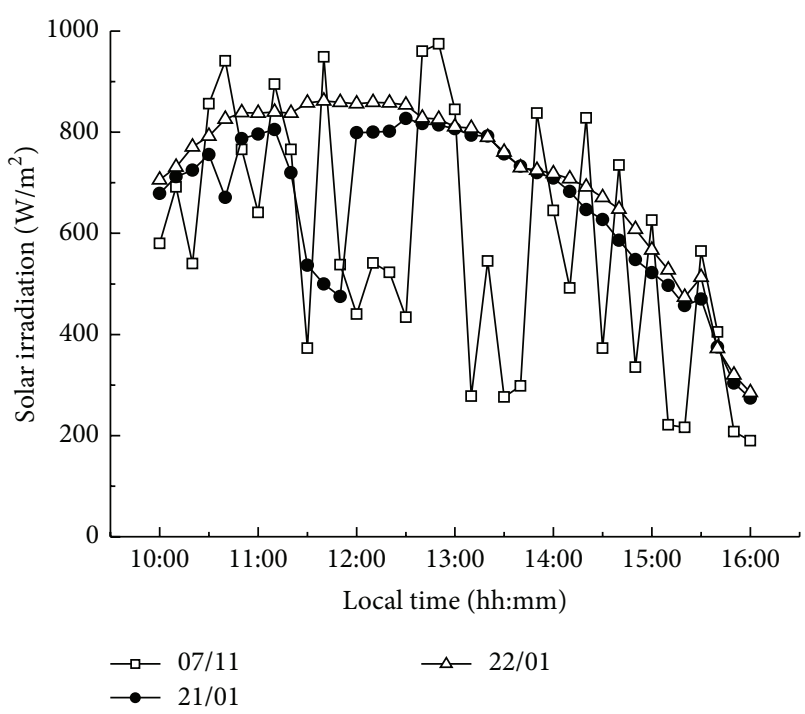

FIGURE 13: Change of solar irradiation with local time.

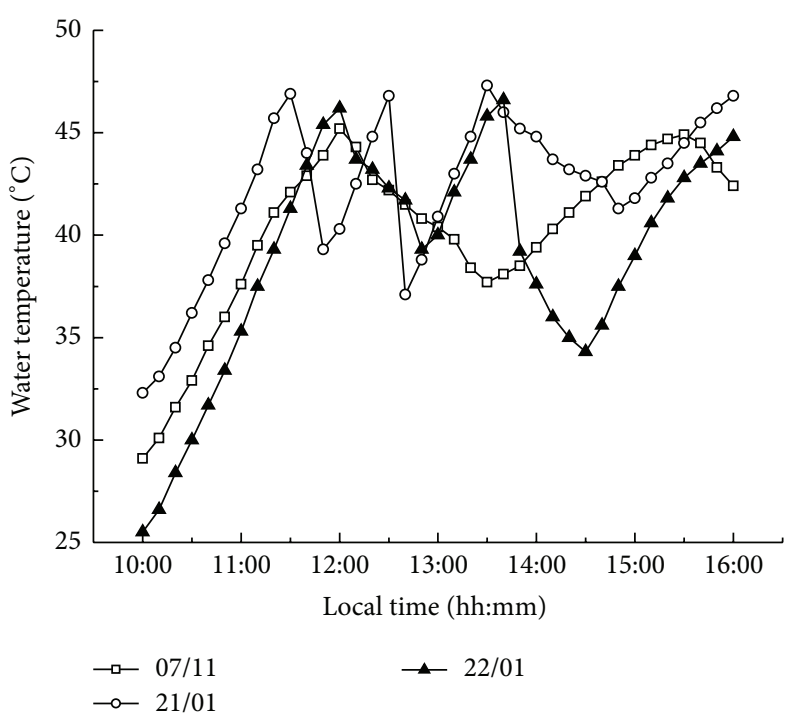

FIGURE 14: Change of water temperature with local time.
Bringing these parameters into efficiency error equation, error can be worked out. The relative uncertainty is $2.6 \%$. By error analysis, the validity of the above method is proved.

\subsubsection{Testing of Hot Water Displacement at a Controlled Tem-} perature. The experiment was also conducted to investigate the thermal performance of the prototype solar collector with a periodical displacement of hot water at a controlled temperature. The system was in nontracking mode. The concentrating trough was fixed with the tilt angle of $50^{\circ}$ in the experiment. Such testing was made on several shiny days with the setting temperature of $45^{\circ} \mathrm{C}$ at which the cold water was fed into the tank to displace hot water. When the temperature of the outflow water reached a certain degree $\left(40^{\circ} \mathrm{C}\right.$ or $\left.35^{\circ} \mathrm{C}\right)$, the water feed was halted. Figures 13 and 14 show the recorded values of solar irradiance and water temperature.

According to (5), the daily average thermal efficiency of the prototype solar collector hot water system on the 22nd of January may be calculated as follows:

$$
\eta_{d}=\frac{C_{p} \cdot \sum_{i} \Delta t_{i} \cdot m_{i}}{A_{c} \cdot H}=0.52,
$$

where $\Delta t_{i}$ is the change of average water temperature between the $i$ th displacement and the $(i-1)$ th displacement and $m_{i}$ is the amount of water for the $i$ th displacement. It is clear that the thermal efficiency of the system with a periodical displacement of hot water is slightly larger than that with a closed water tank. The reason is that the prototype system in the former situation operated at a lower temperature, hence less heat lost to the ambient. In the same way the efficiency on both 7th of November and 21st of January can be obtained being $45 \%$ and $48 \%$. It can be found easily that the efficiency in the controlled temperature mode is bigger due to its operation temperature being lower and heat loss being less.

\section{Conclusions}

In order to overcome the drawback of conventional solar collectors in winter, that is, its unavailability due to low water temperature or even freezing, this paper has presented a new design of solar collectors based on combination of a novel compound curved surface concentrator and an aluminum concentric solar receiver contained in a double-skin glass evacuated tube. A prototype solar collector has been constructed and encapsulated in a glass-covered shell, the cavity which provides an additional thermal insulation. The performance of the prototype has been tested for a sunny winter weather condition and with wall-mounting installation. The experimental results indicate that when the average ambient temperature was below $0^{\circ} \mathrm{C}$ the water temperature can be heated up to $80^{\circ} \mathrm{C}$ with a daily average efficiency of about $50 \%$. Therefore, the designed solar collector could produce useful hot water in winter. The designed solar collector has the following advantages.

(1) The designed solar collector employs a novel compound curved surface concentrator; the number of evacuated tubes used per unit of solar collection area is reduced and so does the amount of heat transfer fluid inside the solar collector. Therefore, the thermal response of the system would be fast. This would be beneficial for application in winter when the period of sunshine is short and the ambient temperature is low.

(2) A heat transfer fluid, which can operate between $-30^{\circ} \mathrm{C}$ and $200^{\circ} \mathrm{C}$, is used to transport the collected solar heat to the water tank through a circulation pump and a heat exchange coil. The heat transfer fluid has a low freezing point and would help to prevent the solar collector from cracking and explosion due to the potential freezing in winter.

(3) The solar collector uses an aluminum concentric pipe as the solar receiver. The fluid channel is directly on the inside of the solar absorption surface, so heat transfer would be fast and efficient. In addition, there is no joint 
between the evacuated tube and the aluminum concentric solar receiver, so this has avoided the difficulty of vacuum keeping for a glass-metal joint.

\section{Conflict of Interests}

The authors declare that there is no conflict of interests regarding the publication of this paper.

\section{Acknowledgment}

This work is supported by the National Natural Science Foundation of China (no. U1261119).

\section{References}

[1] E. Zambolin and D. Del Col, "Experimental analysis of thermal performance of flat plate and evacuated tube solar collectors in stationary standard and daily conditions," Solar Energy, vol. 84, no. 8, pp. 1382-1396, 2010.

[2] K. A. Snail, J. J. O'Gallagher, and R. Winston, "A stationary evacuated collector with integrated concentrator," Solar Energy, vol. 33, no. 5, pp. 441-449, 1984.

[3] A. Rabl, J. O'Gallagher, and R. Winston, "Design and test of non-evacuated solar collectors with compound parabolic concentrators," Solar Energy, vol. 25, no. 4, pp. 335-351, 1980.

[4] M. Li and L. L. Wang, "Investigation of evacuated tube heated by solar trough concentrating system," Energy Conversion and Management, vol. 47, no. 20, pp. 3591-3601, 2006.

[5] D. Jafrancesco, E. Sani, D. Fontani et al., "Simple methods to approximate CPC shape to preserve collection efficiency," International Journal of Photoenergy, vol. 2012, Article ID 863654, 7 pages, 2012.

[6] M. Adsten, A. Helgesson, and B. Karlsson, "Evaluation of CPCcollector designs for stand-alone, roof or wall installation," Solar Energy, vol. 79, no. 6, pp. 638-647, 2005.

[7] B. Norton, P. C. Eames, and Y. P. Yadav, "Symmetric and asymmetric linear compound parabolic concentrating solar energy collectors: the state-of-the-art in optical and thermophysical analysis," International Journal of Ambient Energy, vol. 12, no. 4, pp. 171-190, 1991.

[8] J. Ji, J. Han, T.-T. Chow et al., "Effect of fluid flow and packing factor on energy performance of a wall-mounted hybrid photovoltaic/water-heating collector system," Energy and Buildings, vol. 38, no. 12, pp. 1380-1387, 2006.

[9] W. M. Shen, "Balcony wall type solar water heaters: promote the combination of solar water heaters and building energy efficiency," Transactions of the CSAE, vol. 22, pp. 194-198, 2006.

[10] D. R. Mills, A. Monger, and G. L. Morrison, "Comparison of fixed asymmetrical and symmetrical reflectors for evacuated tube solar receivers," Solar Energy, vol. 53, no. 1, pp. 91-104, 1994.

[11] Y. Tripanagnostopoulos, P. Yianoulis, S. Papaefthimiou, and S. Zafeiratos, "CPC solar collectors with flat bifacial absorbers," Solar energy, vol. 69, no. 3, pp. 191-203, 2000.

[12] H. Zinian, "Study on unsteady-state efficiency equations for solar water heaters," Journal of Acta Energiae Solaris Sinica, vol. 13, pp. 1-7, 1992.

[13] J. H. Li and Q. Jiang, "Experimental research on a high efficient flat plate solar collector," Journal of Acta Energiae Solaris Sinica, vol. 22, no. 2, pp. 131-135, 2001.
[14] S.-Y. Yan, R. Tian, S. Hou, and L.-N. Zhang, "Analysis on unsteady state efficiency of glass evacuated solar collector with an inserted heat pipe," Journal of Engineering Thermophysics, vol. 29, no. 2, pp. 323-326, 2008. 

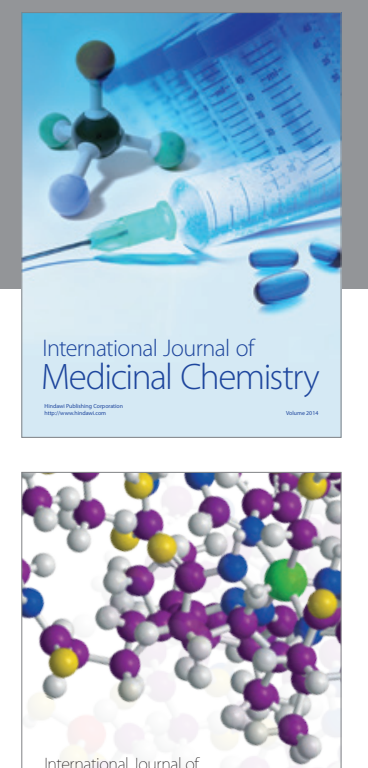

\section{Carbohydrate} Chemistry

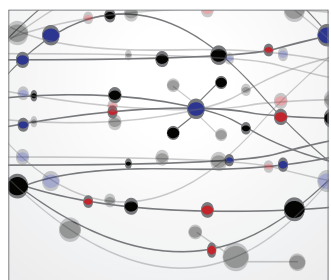

The Scientific World Journal
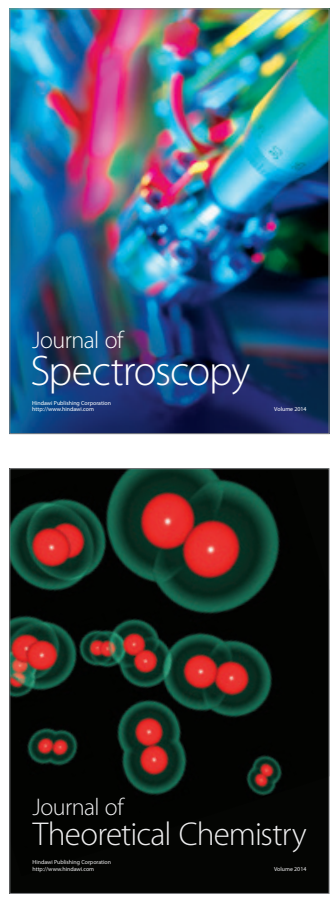
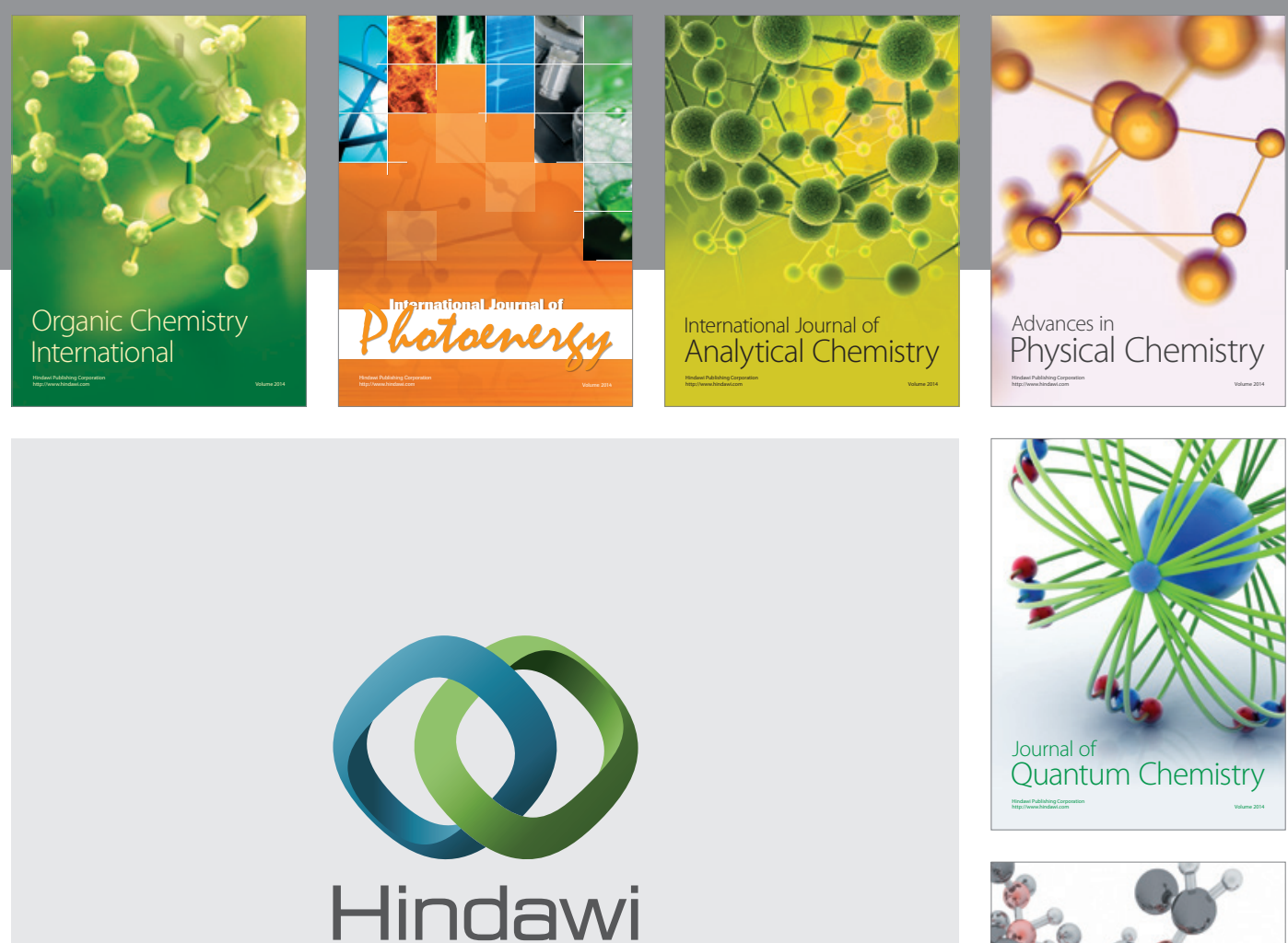

Submit your manuscripts at

http://www.hindawi.com

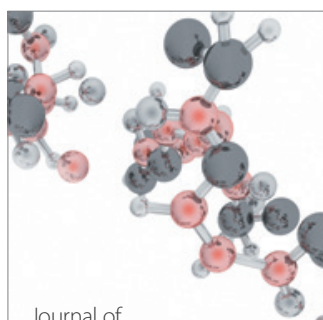

Analytical Methods

in Chemistry

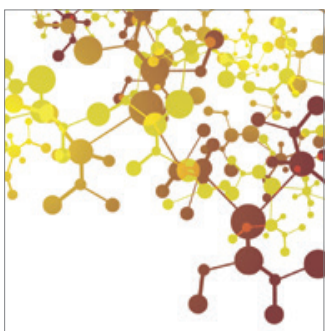

Journal of

Applied Chemistry

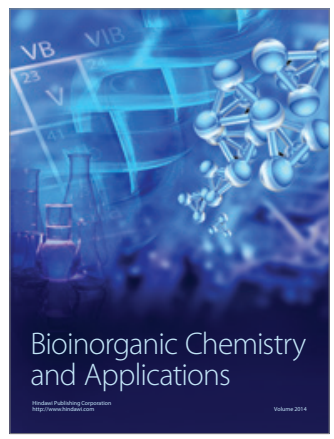

Inorganic Chemistry
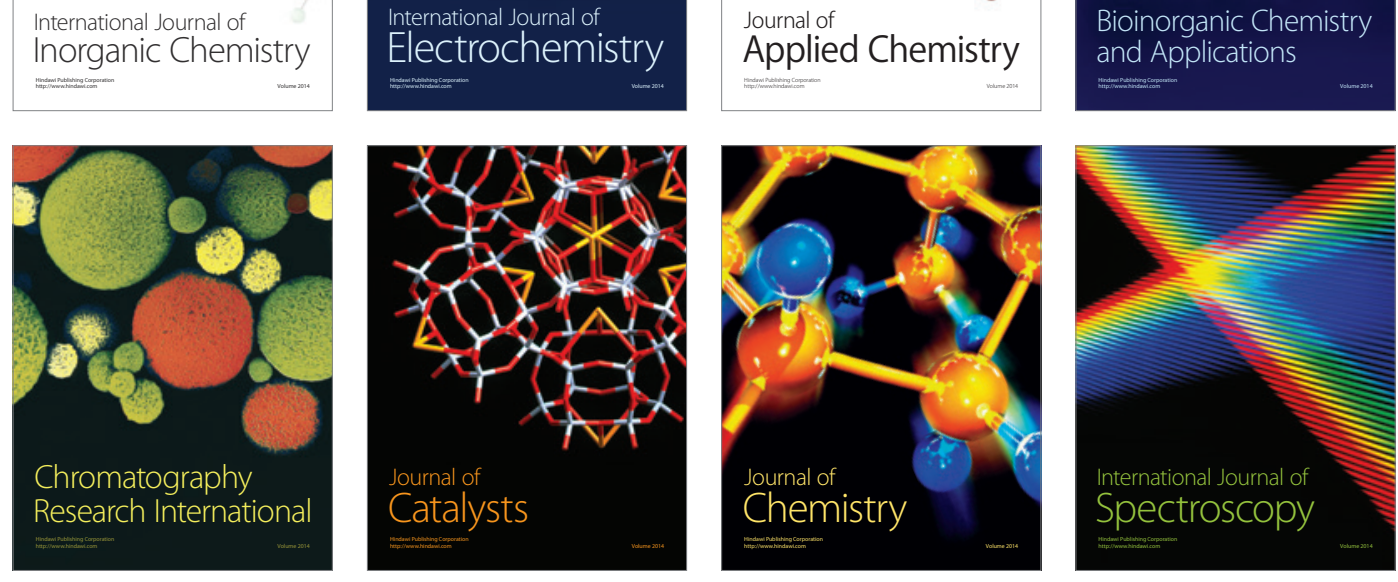